\title{
Pharmacokinetics of DFN-15, a Novel Oral Solution of Celecoxib, Versus Celecoxib 400-mg Capsules: A Randomized Crossover Study in Fasting Healthy Volunteers
}

\author{
Arindam Pal $^{1} \cdot$ Srinivas Shenoy $^{1} \cdot$ Anirudh Gautam $^{2} \cdot$ Sagar Munjal $^{3} \cdot$ \\ Jing $\mathrm{Niu}^{4} \cdot$ Mathangi Gopalakrishnan ${ }^{4} \cdot$ Joga Gobburru $^{4}$
}

Published online: 26 July 2017

(C) The Author(s) 2017. This article is an open access publication

\begin{abstract}
Background COX-2 inhibitors can be effective for acute migraine, but none is supplied in a rapidly absorbed, readyto-use oral liquid formulation. DFN-15, a novel oral liquid formulation of celecoxib, is being developed for the acute treatment of migraine with or without aura. Clinical studies with this formulation are ongoing.
\end{abstract}

Arindam Pal

arindamp@drreddys.com

Srinivas Shenoy

srinivasshenoyb@drreddys.com

Anirudh Gautam

anirudhg@drreddys.com

Sagar Munjal

smunjal@drreddys.com

Jing Niu

niujing23@gmail.com

Mathangi Gopalakrishnan

mgopalakrishnan@rx.umaryland.edu

Joga Gobburru

jgobburu@rx.umaryland.edu

1 Proprietary Products, Dr. Reddy's Laboratories Ltd., Innovation Plaza, Survey Nos. 42, 44, 45 and 54, Quthubullapur, Bachupally, RR Dist, Hyderabad, Telangana 500090, India

2 Proprietary Products, Dr. Reddy's Laboratories SA, Elisabethenanlage 11, 4051 Basel, Switzerland

3 Dr. Reddy's Laboratories, Inc., 107 College Road East, Princeton, NJ 08540, USA

4 Center for Translational Medicine, University of Maryland, Baltimore, MD, USA
Objectives The objectives of the present study were to compare the bioavailability of DFN-15 with that of the commercial formulation of celecoxib 400-mg oral capsules $\left(\right.$ Celebrex $\left.{ }^{\circledR}\right)$ and to determine the dose proportionality of DFN-15 in healthy fasted volunteers.

Methods This single-dose randomized crossover study in 16 healthy fasted volunteers evaluated the pharmacokinetics and relative bioavailability of DFN-15 at doses of 120,180 , and $240 \mathrm{mg}$ against the commercial formulation of celecoxib 400-mg oral capsules and determined the dose proportionality of DFN-15.

Results The maximum observed plasma concentrations $\left(C_{\max }\right)$ of celecoxib after the administration of DFN-15 120,180 , and $240 \mathrm{mg}(1062-1933 \mathrm{ng} / \mathrm{ml})$ were higher than for the 400-mg oral capsules $(611 \mathrm{ng} / \mathrm{ml})$. The median time to peak concentration $\left(T_{\max }\right)$ was within $1 \mathrm{~h}$ for DFN-15 and $2.5 \mathrm{~h}$ for the oral capsules. The pharmacokinetics of DFN-15 were dose proportional from 120 to $240 \mathrm{mg}$. Partial area under the plasma concentration-time curves (AUCs) from $15 \mathrm{~min}$ to $2 \mathrm{~h}$ for DFN-15 $120 \mathrm{mg}$ were at least threefold higher than for the oral capsules, and the relative bioavailability of DFN-15 was approximately $140 \%$ that of the oral capsules. DFN-15 was well tolerated, with no new or unexpected adverse events.

Conclusions Based on a faster rate of absorption and increased bioavailability, DFN-15 is being evaluated as an abortive medication for acute treatment in patients with migraine. 


\section{Key Points}

This study compared the bioavailability of DFN-15, a novel oral liquid formulation of celecoxib, relative to celecoxib 400-mg oral capsules and determined the dose proportionality of DFN-15.

After administration of DFN-15 120, 180, and $240 \mathrm{mg}$, maximum observed plasma concentration $\left(C_{\text {max }}\right)$ values $(1062-1933 \mathrm{ng} / \mathrm{ml})$ were higher than for the 400-mg oral capsules $(611 \mathrm{ng} / \mathrm{ml})$, and the median time to peak concentration $\left(T_{\max }\right)$ was within $1 \mathrm{~h}$ for DFN-15 and $2.5 \mathrm{~h}$ for the oral capsules.

DFN-15 is being evaluated as an acute treatment for migraine based on its faster absorption and greater bioavailability than celecoxib 400-mg oral capsules.

\section{Introduction}

Migraine is a painful, often disabling neurologic condition for which evidence-based acute pharmacotherapy may involve analgesics, nonsteroidal anti-inflammatory drugs (NSAIDs), or migraine-specific drugs (i.e., triptans and dihydroergotamine) [1, 2]. Orally administered NSAIDs are recommended as first-line therapy for attacks of mild to moderate intensity as well as for severe acute attacks [1, 2], and they remain the most commonly used migraine medications [3, 4]. Their efficacy in migraine is based on blockade of cyclooxygenase (COX), which decreases prostaglandin synthesis, but their clinical utility can be limited by upper gastrointestinal complications related to nonselective inhibition of COX-1 isoenzymes in the gastric mucosa [5].

Agents classified as $\mathrm{COX}-2$ selective inhibitors are up to 1000 times more selective for COX-2 than for COX-1 [6], which provides improved gastrointestinal safety relative to nonselective NSAIDs [5, 7-9]. In the acute treatment of migraine, several oral COX-2 inhibitors, including rofecoxib 25 and $50 \mathrm{mg}$ [10], valdecoxib $40 \mathrm{mg}$ [11], and celecoxib $400 \mathrm{mg}$ [9], have demonstrated good efficacy and tolerability. Among the COX-2-selective inhibitors, celecoxib has demonstrated a substantially lower risk of upper gastrointestinal bleeding than rofecoxib [5].

Celecoxib oral capsules (Celebrex ${ }^{\circledR}$, Pfizer Inc., USA), when administered under fasting conditions, achieve peak plasma concentrations $\left(C_{\max }\right)$ at approximately $3 \mathrm{~h}$ [12]. Celecoxib is highly protein bound $(\sim 97 \%)$ within the therapeutic range, and the apparent volume of distribution
$\left(V_{\mathrm{d}} / F\right)$ at steady state is about $400 \mathrm{~L}$, suggesting extensive tissue distribution [12]. Celecoxib is predominantly cleared via the cytochrome P450 (CYP)-2C9 metabolic pathway, with little unchanged drug recovered in urine and feces [12]. The apparent plasma clearance $(\mathrm{Cl} / F)$ is about $500 \mathrm{ml} / \mathrm{min}$ [12]. It appears that its low solubility prolongs celecoxib absorption, making terminal half-life $\left(t_{1 / 2}\right)$ determinations variable and resulting in an effective half-life of about $11 \mathrm{~h}$ under fasted conditions. Delayed oral absorption also slows onset of action and impedes an important treatment goal of acute migraine therapy (i.e., rapid pain relief [13]), and the problem can be exacerbated by migraine-associated gastric stasis, which can inhibit drug absorption and further delay the onset of pain relief with oral medications [14-17].

DFN-15, a novel oral liquid formulation of celecoxib, is being developed for the acute treatment of migraine with or without aura. No COX-2 inhibitors are supplied in a readyto-use oral liquid formulation, and, to our knowledge, no clinical studies have evaluated an oral liquid formulation of celecoxib in the acute treatment of migraine. The objectives of the present study were to compare the relative bioavailability of DFN-15 with that of the commercial formulation of celecoxib 400-mg oral capsules and determine the dose proportionality of DFN-15 in healthy fasted volunteers.

\section{Methods}

\subsection{Compliance with Ethical Standards}

This study was conducted in compliance with the ethical principles of the Declaration of Helsinki (7th revision, 2013), the International Council for Harmonisation Guideline E6 for Good Clinical Practice, and the US FDA Code of Federal Regulations Title 21 (part 56). The protocol and the informed consent form were reviewed and approved by Quorum Review IRB (Seattle, WA, USA). As this study was a phase I trial of an investigational new drug in healthy volunteers, it did not require online pre-registration. However, it was retrospectively registered at http:// www.clinicaltrials.gov (ClinicalTrials.gov identifier: NCT03051685).

\subsection{Subjects}

In total, 16 subjects who consented were considered for this study, and this sample size was judged sufficient to meet the study objectives and provide an estimate of intra-subject variability. Subjects included healthy men and women aged 18-45 years who had a body mass index (BMI) of $18.5-30 \mathrm{~kg} / \mathrm{m}^{2}$, were non-smokers for at least 3 months 
before enrollment, and had no history of clinically significant disease or evidence of clinically significant findings on physical examination and/or clinical laboratory evaluations (hematology, general biochemistry, coagulation, electrocardiogram, urinalysis, fecal occult blood test). Women could not be pregnant or lactating, and those of childbearing potential had to be using appropriate contraceptive techniques or sexually inactive from at least 28 days before through at least 30 days after administration of study drugs.

Subjects were excluded if they were hypersensitive to celecoxib, sulfonamides, or any other NSAIDs or had significant illness or any other condition known to affect drug absorption, distribution, metabolism, and excretion. They were also disqualified for using aspirin or NSAIDs in the 7 days before the study or, in the 28 days before the study, for using enzyme-modifying drugs or another investigational product or having any clinically significant illness. Subjects were also ineligible if they had any significant history of drug dependency or alcohol abuse within the previous year or a positive result on alcohol/drug screen.

\subsection{Study Conduct}

This was a single-center, open-label, randomized, singledose, four-treatment, four-period, four-sequence crossover study. Subjects arrived at the clinical site (Algorithme Pharma USA, Fargo, ND, USA) at least $13 \mathrm{~h}$ prior to drug administration, and they completed an overnight fast for at least $10 \mathrm{~h}$ before drug administration. After each of the three DFN-15 treatments, and together with the celecoxib capsule administration, subjects were given approximately $240 \mathrm{ml}$ of room-temperature water. Subjects remained seated or ambulatory, avoided vigorous exertion and complete rest, and continued fasting for $4 \mathrm{~h}$ after treatment. In each study period, blood samples for pharmacokinetic measurements were collected in a 4-ml vacuum tube with K3-EDTA as anticoagulant at baseline, at 5, 10, 20, 30, 40,60, 80, and $100 \mathrm{~min}$, and at 2, 2.5, 3, 3.5, 4, 5, 6, 8, 12, 24, 48, and $72 \mathrm{~h}$ post-dose. Blood samples were centrifuged at $4{ }^{\circ} \mathrm{C}$ (approximately $3000 \mathrm{rpm}$ for $10 \mathrm{~min}$ ) and as soon as possible and not exceeding $60 \mathrm{~min}$ after blood sample collection. The plasma obtained was transferred in pre-labelled polypropylene tubes and were maintained in an ice-water bath until stored in the clinical freezers pending analysis. Aside from the water taken with the drug, subjects were allowed to consume water until $1 \mathrm{~h}$ before and beginning $1 \mathrm{~h}$ after drug administration. Subjects were checked out of the clinical site $24 \mathrm{~h}$ after each treatment administration and were asked to return for each of the remaining blood samples. The washout period between treatments was 7 days; the duration of the study was 26 days.

\subsection{Treatments}

Subjects were randomized to receive a single $120-\mathrm{mg}$ $(2.4 \mathrm{ml}), 180-\mathrm{mg}(3.6 \mathrm{ml})$, or $240-\mathrm{mg}(4.8 \mathrm{ml})$ dose of $50 \mathrm{mg} / \mathrm{ml}$ DFN-15 oral solution (manufactured by Quay Pharmaceuticals Ltd., UK for Dr. Reddy's Laboratories Ltd., India) or a single 400-mg oral capsule of celecoxib. The celecoxib oral solution was manufactured in compliance with Good Manufacturing Practices and contained excipients that are within the acceptable limits of the federal inactive ingredients database [18]; therefore, no additional nonclinical study was required to assess safety. Dose selection was based on the established pharmacokinetic and safety profiles of celecoxib after a dose of 400-mg oral capsules, and similar exposures were expected with the highest dose $(240 \mathrm{mg})$ of DFN-15. To determine dose proportionality of DFN-15, two additional doses of $120 \mathrm{mg}$ and $180 \mathrm{mg}$ were also selected. Disposable dosing syringes of $5 \mathrm{ml}$ capacity were used to draw appropriate volumes of DFN-15, and the treatments were delivered through the dosing syringe directly into subjects' mouths followed by intake of $240 \mathrm{ml}$ of water. Study medications were administered consecutively, and treatment compliance was confirmed by checking each subject's mouth cavity after drug administration.

\subsection{Drug Assays}

The experimental plasma samples were assayed for celecoxib using a validated bioanalytical method that complies with the FDA guidance [19]. They were analyzed using liquid chromatography (LC), and the analytes were detected using tandem mass-spectrometry (MS/MS). The quantifiable range was $10.393-4059.936 \mathrm{ng} / \mathrm{ml}$. Celecoxib was extracted from $200 \mu$ l anticoagulated (K3-EDTA) human plasma using a precipitation extraction procedure. Celecoxib-d7 was used as an internal standard (IS). The validation was performed using an API $4000^{\mathrm{TM}}$ LC/MS/MS system with a TurboIonSpray ${ }^{\circledR}$ interface (SCIEX, Framingham, MA, USA). The negative ions were measured in multiple reaction monitoring (MRM) mode. The data were acquired and analyzed with Analyst ${ }^{\circledR}$ software, version 1.4.2 (SCIEX). The pump flow was isocratic. The column temperature was kept at $40{ }^{\circ} \mathrm{C}$. Injection volume was $2 \mu \mathrm{l}$ with a total run time of 4 min. The calibration curve consisted of two control blanks, two zero standards, and eight non-zero calibration standards covering the quantifiable concentration range. The quality control (QC) samples were analyzed with every precision and accuracy assay batch. Analyte:IS peak area ratio values were used to set up the calibration curve and to determine QC sample concentrations. The precision and accuracy of back-calculated concentrations of celecoxib calibration standards ranged 
from 0.7 to $6.1 \%$ and from 92.7 to $107.4 \%$, respectively. Inter-assay precision was $3.9-6.7 \%$, while inter-assay accuracy was $94.2-97.8 \%$ (for QC samples). The intraassay precision value of QCs ranged from 1.7 to $5.7 \%$, whereas intra-assay accuracy ranged from 90.1 to $103.6 \%$ (for QC samples).

\subsection{Pharmacokinetic and Statistical Analyses}

The primary pharmacokinetic parameters of interest were $C_{\max }$, area under the plasma concentration-time curve (AUC) from baseline through $15 \mathrm{~min}$ post-dose $\left(\mathrm{AUC}_{0-15 \mathrm{~min}}\right)$, AUC from baseline through 30 min postdose $\left(\mathrm{AUC}_{0-30 \mathrm{~min}}\right)$, AUC from baseline through $1 \mathrm{~h}$ postdose $\left(\mathrm{AUC}_{0-1 \mathrm{~h}}\right)$, AUC from baseline through $2 \mathrm{~h}$ postdose $\left(\mathrm{AUC}_{0-2 \mathrm{~h}}\right)$, AUC from baseline through the last measured concentration $\left(\mathrm{AUC}_{0-T}\right)$, AUC from baseline

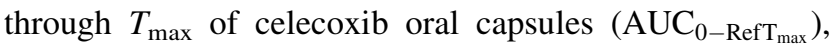
and AUC extrapolated to infinity $\left(\mathrm{AUC}_{0-\infty}\right)$. Secondary parameters included time before the first measurable concentration $\left(T_{\text {lag }}\right), T_{\max }$, relative percentage of $\mathrm{AUC}_{0-T}$ with respect to $\mathrm{AUC}_{0-\infty}\left(\mathrm{AUC}_{0-T / \infty}\right)$, apparent elimination rate constant $\left(\lambda_{\mathrm{Z}}\right)$, and $t_{1 / 2}$. Since each of the DFN-15 doses was compared with an oral dose of celecoxib $400 \mathrm{mg}$, samples from subjects who provided evaluable data for at least one of the comparisons of interest or for the dose proportionality evaluation were assayed. Data from these subjects were included in the pharmacokinetic and statistical analysis.

AUC parameters were not estimated for subjects with fewer than three consecutive measurable concentrations of celecoxib in a study period. Data for subjects whose samples were not taken within $2 \mathrm{~min}$ of the $20-$ or $30-\mathrm{min}$ timepoints and/or 5\% of the 1- and 2-h timepoints (i.e., $3 \mathrm{~min}$ at $1 \mathrm{~h}$ and $6 \mathrm{~min}$ at $2 \mathrm{~h}$ ) were excluded from the calculations for the parameters $\mathrm{AUC}_{0-15 \min }, \mathrm{AUC}_{0-30 \mathrm{~min}}$, $\mathrm{AUC}_{0-1 \mathrm{~h}}$, and/or $\mathrm{AUC}_{0-2 \mathrm{~h}}$.

Pharmacokinetic parameters were estimated using a non-compartmental approach with a log-linear terminal phase assumption. The linear-up and log-down trapezoidal method was used to estimate AUCs. Disposition parameters were not estimated for individual concentration-time profiles if the terminal log-linear phase could not be reliably characterized. Pharmacokinetic analyses were performed using validated software (Phoenix ${ }^{\circledR}$ WinNonlin ${ }^{\circledR}$ version 6.3; Certara USA, Inc., Princeton, NJ, USA), and workflows were reported with the help of Phoenix ${ }^{\circledR}$ Connect $^{\mathrm{TM}}$ version 1.3.1 (Certara USA, Inc., Princeton, NJ, USA).

Descriptive statistics were used to summarize adverse events (AEs), safety results, and demographic variables (age, height, weight, and BMI). The natural logarithmic transformation of primary pharmacokinetic parameters, as well as the rank-transformation of $T_{\mathrm{lag}}$ and $T_{\max }$, were used for all statistical inferences.

All primary pharmacokinetic parameters were analyzed using separate analysis of variance (ANOVA) models. The ANOVA model included the treatment received, period of administration, and the sequence in which each treatment was received as fixed factors and the subject effect (nested within sequence) as random factor. Treatment, sequence, and period effects were evaluated at the $5 \%$ significance level $(p<0.05)$.

All three doses of DFN-15 were evaluated for bioavailability $\left(F_{\text {rel }}\right)$ relative to an oral dose of celecoxib $400 \mathrm{mg}$ and calculated as:

$$
\begin{aligned}
F_{\text {rel }}(\%)= & \left(\mathrm{AUC}_{(0-\infty) T i} / \operatorname{Dose}_{T i}\right) /\left(\mathrm{AUC}_{(0-\infty) \mathrm{R}} / \text { Dose }_{\mathrm{R}}\right) \\
& \times 100
\end{aligned}
$$

where $T$ represents DFN-15, $i=1 \ldots n$ represents the dose of DFN-15, and R represents celecoxib oral capsules. Bioavailability was compared using a two one-sided test approach for equivalence determination [20]. The ratio of geometric least-square means (LSMs) with corresponding $90 \%$ confidence interval (CI) was calculated from the exponential of the difference between each study treatment for the ln-transformed primary parameters. The statistical analyses were performed with SAS ${ }^{\circledR}$ version 9.4 using the mixed procedure and REG procedure (SAS Institute, Cary, NC, USA).

\subsection{Dose-Proportionality Assessment}

A dose-proportionality analysis was performed on the dose-normalized $C_{\max }, \mathrm{AUC}_{0-2 \mathrm{~h}}, \mathrm{AUC}_{0-T}$, and $\mathrm{AUC}_{0-\infty}$ parameters of the DFN-15 120-, 180-, and 240-mg treatments. These pharmacokinetic parameters were entered in a power model defined as:

$$
\begin{aligned}
& \ln \left(C_{\max }, \mathrm{AUC}_{0-2 \mathrm{~h}}, \mathrm{AUC}_{0-T}, \text { or } \mathrm{AUC}_{0-\infty}\right) \\
& \quad=\alpha+\beta \cdot \ln (\text { Dose })+\varepsilon
\end{aligned}
$$

where $\alpha$ is the intercept, $\beta$ is the slope, and $\varepsilon$ is the error term. A linear model with ln-transformed dose as a continuous effect was fitted. A point estimate and a $90 \%$ CI were derived for the slope $(\beta)$. Dose proportionality was considered to have been verified if $\beta$ was not significantly different from 0 at a level of significance of $10 \%$.

\subsection{Safety Assessment}

Safety parameters-the occurrence of AEs; the measurement of clinical laboratory parameters, fecal occult blood tests, vital signs, and electrocardiograms; and physical examinations-were evaluated before, during, and after the study (i.e., after the collection of the last blood sample). Female subjects underwent serum pregnancy tests before, during, and after the study. 


\section{Results}

\subsection{Subjects}

Of the 16 subjects enrolled in the study, 16 (100\%) received DFN-15 $240 \mathrm{mg}$, and 15 subjects (94\%) received DFN-15 $120 \mathrm{mg}$, DFN-15 $180 \mathrm{mg}$, and celecoxib 400-mg oral capsules; 15 subjects (94\%) completed the study. One subject, a 26-year-old male who was discontinued because of a clinically significant decrease in hemoglobin level $(11 \mathrm{~g} / \mathrm{dl})$, only received DFN-15 $240 \mathrm{mg}$. Demographics are shown in Table 1.

\subsection{Treatment Compliance}

The celecoxib doses in DFN-15 were delivered to subjects as planned, with minimal deviation in volume (i.e., within $\pm 5 \%)$.

\subsection{Pharmacokinetics}

The mean plasma concentration-time profiles for DFN-15 $120 \mathrm{mg}$, DFN-15 $180 \mathrm{mg}$, DFN-15 $240 \mathrm{mg}$, and celecoxib 400-mg oral capsules are shown in Fig. 1. Plasma concentrations were below the lower limit of quantification in

Table 1 Subject demographics

\begin{tabular}{ll}
\hline Variable & Value \\
\hline Weight $(\mathrm{kg})$ & $74.4 \pm 11.1$ \\
Age (years) & $27.2 \pm 6.4$ \\
Height $(\mathrm{cm})$ & $172.7 \pm 7.4$ \\
BMI $\left(\mathrm{kg} / \mathrm{m}^{2}\right)$ & $24.9 \pm 2.0$ \\
Sex & \\
Male & $14(88)$ \\
Female & $2(12)$ \\
Race & \\
White & $8(50)$ \\
Black & $5(31)$ \\
Asian & $3(19)$ \\
Ethnicity & \\
Non-Hispanic & $15(94)$ \\
Hispanic & $1(6)$ \\
Alcohol status & \\
Current & $4(25)$ \\
Former or never & $12(75)$ \\
Smoking status & \\
Former & $14(88)$ \\
Never & \\
\hline Date & \\
\hline
\end{tabular}

Data are presented as mean \pm standard deviation or $n(\%)$

$B M I$ body mass index all baseline samples, showing no effect of carry-over from preceding periods. Table 2 summarizes pharmacokinetic parameters for the three DFN-15 doses and celecoxib capsules. DFN-15 had a faster median $T_{\max }$ across the DFN-15 doses than the capsule formulation (40 $\min$ to $1 \mathrm{~h}$ vs. $2.5 \mathrm{~h}$ ). Peak plasma concentrations with the lowest $(120 \mathrm{mg})$ and highest $(240 \mathrm{mg})$ doses of DFN-15 were approximately two to three times higher, respectively, than with celecoxib capsules. The initial partial AUCs for DFN15 (from $\mathrm{AUC}_{0-15 \min }$ to $\mathrm{AUC}_{0-2 \mathrm{~h}}$ ) across the dose range $120-240 \mathrm{mg}$ were at least twice and up to 67 times greater than for celecoxib capsules.

The mean relative bioavailability of the DFN-15 oral solution across the doses tested was about $140 \%$ greater than that of the celecoxib 400-mg capsules. The relative exposures until the median $T_{\max }\left(\mathrm{AUC}_{0-\mathrm{RefT}_{\max }}\right)$ of celecoxib capsules were about 2.2 to 4.5 times higher for DFN15 oral solution than for the oral capsule through doses of $120-240 \mathrm{mg}$. The $t_{1 / 2}$ of celecoxib across the DFN-15 doses was similar, independent of dose, and different from that of the capsule formulation. Overall, the $t_{1 / 2}$ of DFN-15 was always shorter and often about half that of the celecoxib 400-mg capsules. There were differences in the number of subjects for some of the partial AUCs and parameters associated with the terminal phase that could not be calculated because they deviated from study protocol or did not meet the log-linear assumption of terminal phase.

No statistically significant sequence or period effects were observed for any of the pharmacokinetic parameters. Statistically significant treatment effects $(p<0.05)$ were observed for all primary pharmacokinetic parameters and all doses of DFN-15 versus celecoxib 400-mg oral capsules. A statistical comparison of DFN-15 oral solution and celecoxib 400-mg oral capsules is shown in Table 3.

For the dose proportionality of all selected parameters $\left(C_{\max }, \mathrm{AUC}_{0-2 \mathrm{~h}}, \mathrm{AUC}_{0-T}\right.$, and $\left.\mathrm{AUC}_{0-\infty}\right)$, the slope was not significantly different from 0 at the $10 \%$ level, which confirmed proportionality across the three DFN-15 doses (Table 4).

\subsection{Safety}

The incidence of AEs was very low (Table 5). One subject (6\%) reported two AEs after receiving one dose of DFN-15 $240 \mathrm{mg}$. The subject's hemoglobin decreased $(6.3 \%)$, and there was evidence of occult fecal blood $(6.3 \%)$. These AEs were considered mild and not related to DFN-15. One of the AEs, decreased hemoglobin, resolved 17 days later. No other AEs were reported after treatment with DFN-15 $120 \mathrm{mg}$, DFN-15 $180 \mathrm{mg}$, or celecoxib 400-mg oral capsules. There were no reports of drug-related AEs, serious AEs, or deaths in the study. 
Fig. 1 Mean plasma concentration-time profile of DFN-15 and celecoxib oral capsules through $72 \mathrm{~h}$ post-dose on a semi-logarithmic scale, with an inset showing the same measurements through $3 \mathrm{~h}$ postdose. Note at each time point post-dose, individual plasma concentrations were averaged to obtain mean concentrations. Averaging of individual concentrations from five subjects (all concentrations are above the limit of quantitation) on DFN-15 $180 \mathrm{mg}$ at $5 \mathrm{~min}$ post-dose resulted in a value of $5.8 \mathrm{ng} / \mathrm{ml}$

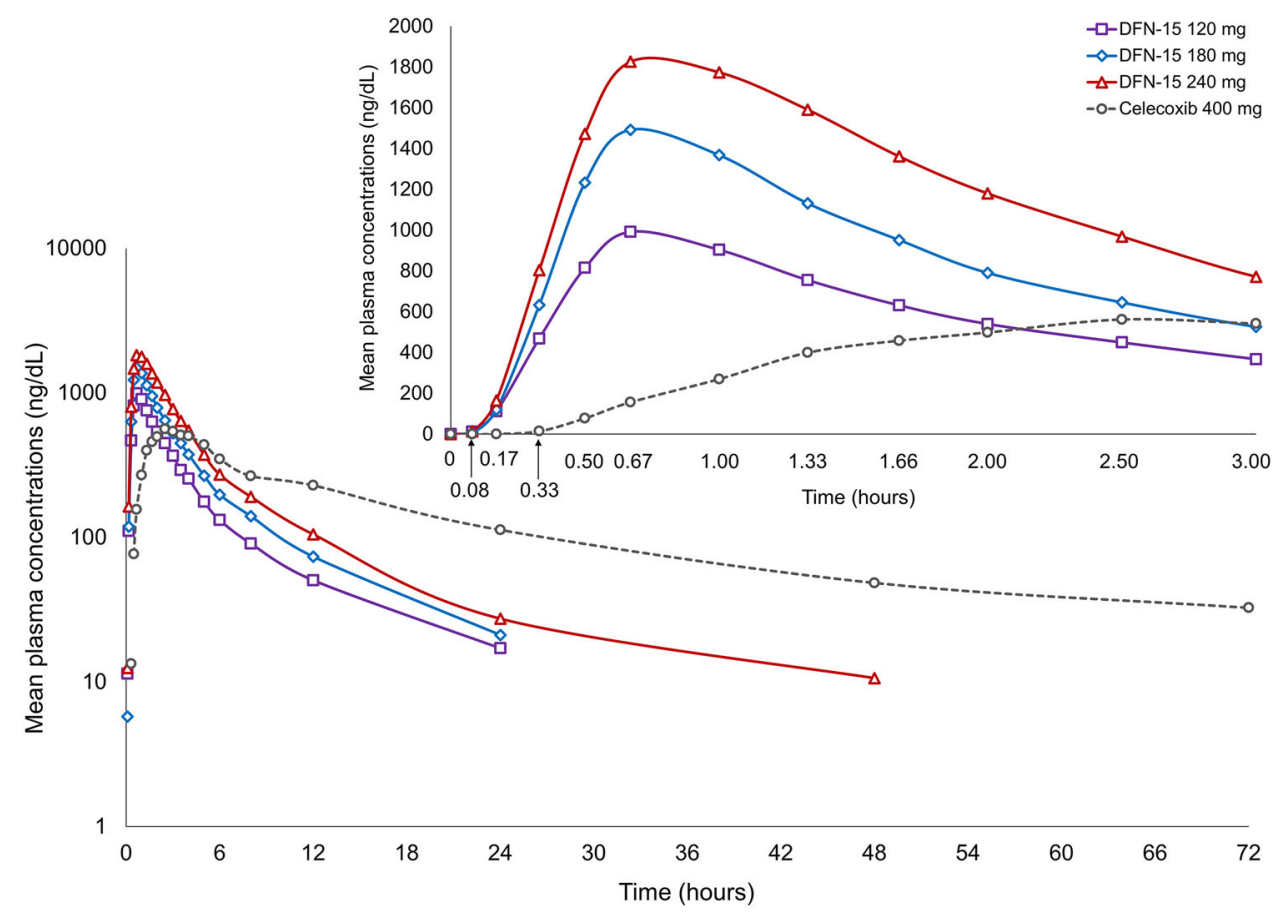

Table 2 Pharmacokinetics of DFN-15 oral solution and celecoxib 400-mg oral capsules

\begin{tabular}{lllll}
\hline Parameters & $\begin{array}{l}\text { DFN-15 } 120 \mathrm{mg} \\
(n=15)\end{array}$ & $\begin{array}{l}\text { DFN-15 180 mg } \\
(n=15)\end{array}$ & $\begin{array}{l}\text { DFN-15 240 mg } \\
(n=16)\end{array}$ & $\begin{array}{l}\text { Oral capsules 400 mg } \\
(n=15)\end{array}$ \\
\hline$C_{\max }(\mathrm{ng} / \mathrm{ml})$ & $1061.9 \pm 237.6$ & $1544.9 \pm 289.9$ & $1932.5 \pm 305.7$ & $611.4 \pm 222.2$ \\
$T_{\max }(\mathrm{h})$ & $0.7(0.5-1.7)$ & $0.7(0.5-1.0)$ & $1.0(0.5-2.0)$ & $2.5(1.7-5.0)$ \\
$T_{\text {lag }}(\mathrm{h})$ & $0.1(0.0-0.1)$ & $0.1(0.0-0.1)$ & $0.1(0.0-0.1)$ & $0.2(0.1-0.3)$ \\
$\mathrm{AUC}_{0-15 \min }(\mathrm{ng} \cdot \mathrm{h} / \mathrm{mL})^{\mathrm{a}}$ & $19.2 \pm 10.7$ & $26.6 \pm 11.8$ & $35.2 \pm 17.8$ & $0.3 \pm 0.3$ \\
$\mathrm{AUC}_{0-30 \min }(\mathrm{ng} \cdot \mathrm{h} / \mathrm{mL})^{\mathrm{a}}$ & $149.1 \pm 51.0$ & $228.0 \pm 68.6$ & $283.2 \pm 80.9$ & $9.5 \pm 5.8$ \\
$\mathrm{AUC}_{0-1 \mathrm{~h}}(\mathrm{ng} \cdot \mathrm{h} / \mathrm{mL})^{\mathrm{b}}$ & $604.8 \pm 165.8$ & $929.5 \pm 193.5$ & $1151.8 \pm 214.1$ & $103.2 \pm 61.8$ \\
AUC $_{0-2 \mathrm{~h}}(\mathrm{ng} \cdot \mathrm{h} / \mathrm{mL})$ & $1322.7 \pm 248.6$ & $1976.9 \pm 382.5$ & $2621.2 \pm 378.9$ & $512.5 \pm 292.1$ \\
$\mathrm{AUC}_{0-\mathrm{RefT}}(\mathrm{ng} \cdot \mathrm{h} / \mathrm{mL})$ & $1569.1 \pm 298.5$ & $2334.2 \pm 462.3$ & $3156.5 \pm 447.9$ & $777.4 \pm 401.7$ \\
AUC $_{0-T}(\mathrm{ng} \cdot \mathrm{h} / \mathrm{mL})$ & $3059.7 \pm 985.2$ & $4633.1 \pm 1478.2$ & $6621.6 \pm 1840.0$ & $7288.0 \pm 2505.8$ \\
AUC $_{0-\infty}(\mathrm{ng} \cdot \mathrm{h} / \mathrm{mL})^{\mathrm{c}}$ & $3476.9 \pm 1176.8$ & $5234.8 \pm 1423.7$ & $6827.7 \pm 1857.5$ & $8074.9 \pm 2159.3$ \\
AUC $_{0-T / \infty}(\%)^{\mathrm{c}}$ & $93.6 \pm 4.7$ & $95.5 \pm 3.3$ & $96.9 \pm 2.2$ & $91.7 \pm 7.6$ \\
$t_{1 / 2}(\mathrm{~h})^{\mathrm{c}}$ & $4.5 \pm 1.6$ & $4.4 \pm 1.5$ & $4.7 \pm 1.6$ & $9.8 \pm 3.1$ \\
Mean relative bioavailability $_{\quad \%}$ & 144 & 144 & 141 & 100
\end{tabular}

$A U C$ area under the plasma concentration-time curve, $A U C_{0-f \text { Ref }_{\max }}$ AUC from baseline through $T_{\max }, A U C_{O-T}$ AUC from baseline through the last measured concentration, $A U C_{0-15 \min }$ AUC from baseline through 15 min post-dose, $A U C_{0-30 \min }$ AUC from baseline through 30 min postdose, $A U C_{0-1 \mathrm{~h}}$ AUC from baseline through $1 \mathrm{~h}$ post-dose, $A U C_{0-2 \mathrm{~h}}$ AUC from baseline through $2 \mathrm{~h}$ post-dose, $A U C_{0-\infty}$ AUC extrapolated to infinity, $A U C_{0-T / \infty} \mathrm{AUC}_{0-T}$ with respect to $\mathrm{AUC}_{0-\infty}, C_{\max }$ maximum observed plasma concentration, $T_{\text {lag }}$ time before the first measurable concentration, $T_{\max }$ time to peak concentration, $t_{1 / 2}$ terminal half-life, $\lambda_{Z}$ apparent elimination rate constant

${ }^{\mathrm{a}} n=11$ for DFN-15 $120 \mathrm{mg}, n=13$ for DFN-15 $180 \mathrm{mg}, n=14$ for DFN-15 $240 \mathrm{mg}$, and $n=13$ for celecoxib $400 \mathrm{mg}$

b $n=12$ for DFN-15 $120 \mathrm{mg}, n=14$ for DFN-15 $180 \mathrm{mg}, n=14$ for DFN-15 $240 \mathrm{mg}$, and $n=14$ for celecoxib $400 \mathrm{mg}$

${ }^{\mathrm{c}} n=11$ for $\lambda_{\mathrm{Z}}, \mathrm{AUC}_{0-\infty}, \mathrm{AUC}_{0-T / \infty}$, and $t_{1 / 2}$ 
Table 3 Statistical comparison of DFN-15 oral solution and celecoxib 400-mg oral capsules

\begin{tabular}{|c|c|c|c|c|c|c|c|c|}
\hline \multirow[t]{2}{*}{ Parameter } & \multicolumn{4}{|c|}{ Geometric LSMs ${ }^{\mathrm{a}}$} & \multirow[t]{2}{*}{ Comparison (mg) } & \multirow[t]{2}{*}{ Ratio (\%) } & \multirow[t]{2}{*}{$90 \%$ CIs } & \multirow[t]{2}{*}{ Intrasubject CV (\%) } \\
\hline & $\begin{array}{l}\text { DFN-15 } \\
120 \mathrm{mg} \\
(n=15)^{\mathrm{b}}\end{array}$ & $\begin{array}{l}\text { DFN-15 } \\
180 \mathrm{mg} \\
(n=15)^{\mathrm{b}}\end{array}$ & $\begin{array}{l}\text { DFN-15 } \\
240 \mathrm{mg} \\
(n=15)^{\mathrm{b}}\end{array}$ & $\begin{array}{l}\text { Oral capsules } \\
400 \mathrm{mg} \\
(n=15)^{\mathrm{b}}\end{array}$ & & & & \\
\hline$C_{\max }$ & 1041.4 & 1512.5 & 1899.0 & 565.9 & $\begin{array}{l}120 \text { vs. } 400 \\
180 \text { vs. } 400 \\
240 \text { vs. } 400\end{array}$ & $\begin{array}{l}184.0 \\
267.3 \\
335.6\end{array}$ & $\begin{array}{l}159.4-212.4 \\
231.5-308.5 \\
290.7-387.4\end{array}$ & 23.6 \\
\hline $\mathrm{AUC}_{0-2 \mathrm{~h}}{ }^{\mathrm{c}}$ & 1291.4 & 1920.1 & 2558.5 & 433.2 & $\begin{array}{l}120 \text { vs. } 400 \\
180 \text { vs. } 400 \\
240 \text { vs. } 400\end{array}$ & $\begin{array}{l}298.1 \\
443.2 \\
590.6\end{array}$ & $\begin{array}{l}245.7-361.7 \\
365.3-537.8 \\
486.8-716.6\end{array}$ & 32.1 \\
\hline $\mathrm{AUC}_{0-\mathrm{RefT}_{\max }}$ & 1530.4 & 2264.3 & 3071.6 & 680.2 & $\begin{array}{l}120 \text { vs. } 400 \\
180 \text { vs. } 400 \\
240 \text { vs. } 400\end{array}$ & $\begin{array}{l}225.0 \\
332.9 \\
451.6\end{array}$ & $\begin{array}{l}191.0-265.0 \\
282.6-392.1 \\
383.4-531.9\end{array}$ & 27.0 \\
\hline $\mathrm{AUC}_{0-T}$ & 2890.1 & 4385.0 & 6137.1 & 6789.6 & $\begin{array}{l}120 \text { vs. } 400 \\
180 \text { vs. } 400 \\
240 \text { vs. } 400\end{array}$ & $\begin{array}{l}42.6 \\
64.6 \\
90.4\end{array}$ & $\begin{array}{l}39.3-46.2 \\
59.6-70.0 \\
83.4-98.0\end{array}$ & 13.2 \\
\hline $\mathrm{AUC}_{0-\infty}$ & 3254.9 & 4977.2 & 6763.2 & 7783.8 & $\begin{array}{l}120 \text { vs. } 400 \\
180 \text { vs. } 400 \\
240 \text { vs. } 400\end{array}$ & $\begin{array}{l}41.8 \\
63.9 \\
86.9\end{array}$ & $\begin{array}{l}38.6-45.3 \\
59.1-69.3 \\
80.2-94.1\end{array}$ & 11.5 \\
\hline
\end{tabular}

$A U C$ area under the plasma concentration-time curve, $\mathrm{AUC}_{0-\mathrm{RefT}_{\max }} \mathrm{AUC}$ from baseline through $T_{\max }, A U C_{0-T}$ AUC from baseline through the last measured concentration, $A U C_{0-2 \mathrm{~h}} \mathrm{AUC}$ from baseline through $2 \mathrm{~h}$ post-dose, $A U C_{0-\infty} \mathrm{AUC}$ extrapolated to infinity, $A U C_{0-T / \infty} \mathrm{AUC}_{0-T}$ with respect to $\mathrm{AUC}_{0-\infty}, C I$ confidence interval, $C_{\text {max }}$ maximum observed plasma concentration, $C V$ coefficient of variation, $L S M$ least-square means, $T_{\text {max }}$ time to peak concentration, $t_{1 / 2}$ terminal half-life, $\lambda_{Z}$ apparent elimination rate constant

${ }^{\text {a }}$ Values are $\mathrm{ng} / \mathrm{ml}$ for $C_{\max }$ and $\mathrm{ng} \cdot \mathrm{h} / \mathrm{mL}$ for AUCs

${ }^{\mathrm{b}} n=11$ for $\lambda_{\mathrm{Z}}, \mathrm{AUC}_{0-\infty}, \mathrm{AUC}_{0-T / \infty}$, and $\mathrm{t}_{1 / 2}$

${ }^{c} n=12$ for DFN-15 $120 \mathrm{mg}, n=14$ for DFN-15 $180 \mathrm{mg}, n=12$ for DFN-15 $240 \mathrm{mg}$, and $n=14$ for celecoxib 400 -mg oral capsules

Table 4 Dose proportionality parameters

\begin{tabular}{llrl}
\hline Parameters & $\alpha$ & $\beta(90 \% \mathrm{CI})$ & $\varepsilon$ \\
\hline$C_{\max }$ & 2.727 & $-0.118(-0.29$ to 0.052$)$ & 0.038 \\
AUC $_{0-2 \mathrm{~h}}$ & 2.406 & $-0.001(-0.159$ to 0.150$)$ & 0.032 \\
$\mathrm{AUC}_{0-T}$ & 2.588 & $0.124(-0.132$ to 0.380$)$ & 0.087 \\
AUC $_{0-\infty}$ & 2.867 & $0.079(-0.176$ to 0.334$)$ & 0.086
\end{tabular}

$A U C$ area under the plasma concentration-time curve, $A U C_{O-T}$ AUC from baseline through the last measured concentration, $A U C_{0-2 h} \mathrm{AUC}$ from baseline through $2 \mathrm{~h}$ post-dose, $A U C_{0-\infty}$ AUC extrapolated to infinity, $C I$ confidence interval

\section{Discussion}

In this single-dose bioavailability study in healthy volunteers, celecoxib pharmacokinetics from three doses $(120$, 180 , and $240 \mathrm{mg}$ ) of DFN-15 were evaluated and compared with the highest dose of marketed capsule formulation of celecoxib. The rapid rate of absorption from the oral solution was demonstrated: DFN-15 exhibited higher initial partial AUCs and $\mathrm{AUC}_{0-\mathrm{RefT}_{\max }}$ than did the oral capsules. On the $\mathrm{AUC}_{0-2 \mathrm{~h}}$ parameter (a commonly used index for 2-h pain freedom and pain relief $[21,22])$, DFN-15
120-240 mg was about three to six times higher than celecoxib oral capsules. These results indicate that DFN-15 overcomes the solubility limitation in celecoxib absorption [12] from celecoxib oral capsules and suggest the possibility of a rapid onset of action. DFN-15 oral solution exhibited dose-proportional bioavailability from 120 to $240 \mathrm{mg}$. Higher aqueous solubility and consequent rapid and improved absorption of celecoxib from the DFN-15 oral solution shortened its $t_{1 / 2}$ to about half that of the capsule formulation. The celecoxib capsule has poor aqueous solubility with extended absorption and thus resulting a variable elimination phase.

Intra-subject variabilities for the exposure parameters were found to be low to moderate, with a maximum variability of $32 \%$ for $\mathrm{AUC}_{0-2 \mathrm{~h}}$. Subjects in the oral capsules group showed more variability at $\mathrm{AUC}_{0-2 \mathrm{~h}}(\%$ coefficient of variation, or standard deviation/mean $\times 100=57$ ) than those in the oral solution group (14-19\%); when all the treatments were pooled for ANOVA, this higher variability inflated the overall result.

The present study was conducted in a small representative population of healthy US volunteers and found that 
Table 5 Summary of adverse events

\begin{tabular}{lllll}
\hline Event & $\begin{array}{l}\text { DFN-15 } \\
120 \mathrm{mg} \\
(n=15)\end{array}$ & $\begin{array}{l}\text { DFN-15 } \\
(n=\mathrm{mg} \\
(n=15)\end{array}$ & $\begin{array}{l}\text { DFN-15 } \\
(n=10 \mathrm{mg}\end{array}$ & $\begin{array}{l}\text { Oral capsules } \\
400 \mathrm{mg} \\
(n=15)\end{array}$ \\
\hline Subjects with one or more AE & 0 & 0 & $1(6.3)$ & 0 \\
Investigations & 0 & 0 & $1(6.3)$ & 0 \\
Hemoglobin decreased & 0 & 0 & $1(6.3)$ & 0 \\
Occult blood positive & 0 & 0 & $1(6.3)$ & 0 \\
\hline
\end{tabular}

Data are presented as $n(\%)$

$A E$ adverse event

the $C_{\max }$ of celecoxib 400-mg capsules was lower than the $C_{\max }$ reported for 200-mg oral capsules in the fasting state (i.e., $705 \mathrm{ng} / \mathrm{ml}$ ) [12]. In separate studies of oral celecoxib $200 \mathrm{mg}$ in healthy Thai and Indian volunteers, researchers reported $C_{\max }$ values of 687 and $545 \mathrm{ng} / \mathrm{ml}$, respectively, and $\mathrm{AUC}_{0-\infty}$ values of 5912 and $4632 \mathrm{ng} \cdot \mathrm{h} / \mathrm{mL}$, respectively $[23,24]$. Since $V_{\mathrm{d}} / F$ and $\mathrm{Cl} / F$ are considered indicators of plasma concentrations and exposure, respectively, these parameters from previously reported studies were compared with those from the current study. In these studies, the mean $V_{\mathrm{d}} / F$ was $459 \mathrm{~L}$ (Thai) and $583 \mathrm{~L}$ (Indian) $[23,24]$, which parallels the previously reported $V_{\mathrm{d}} l$ $F$ of $429 \mathrm{~L}$ [12]. The mean $\mathrm{Cl} / F$ from these studies ranged from 36 to $43 \mathrm{~L} / \mathrm{h}[23,24]$, which is higher than the reported $\mathrm{Cl} / F$ of $27.7 \mathrm{~L} / \mathrm{h}[12]$. The results for $V_{\mathrm{d}} / F$ and $\mathrm{Cl} /$ $F$ in the present study $(743 \mathrm{~L}$ and $52 \mathrm{~L} / \mathrm{h}$ ) deviated widely from the reported values [12], as well as from those in the study of Thai volunteers [23], but were relatively closer to those in the study of Indian volunteers [24]. Since $V_{\mathrm{d}} / F$ is directly related to body weight and surface area, a lower average BMI in the studies involving Thai $\left(21 \mathrm{~kg} / \mathrm{m}^{2}\right)$ and Indian $\left(23 \mathrm{~kg} / \mathrm{m}^{2}\right)$ volunteers compared with the current study volunteers $\left(24.9 \mathrm{~kg} / \mathrm{m}^{2}\right)$ might have resulted in higher $C_{\max }$ values. This possibility cannot be investigated, as the body weight and BMI of study participants in the reported study $\left(C_{\max } \sim 705 \mathrm{ng} / \mathrm{ml}\right)$ does not appear to have been recorded [12]. Population distribution data suggest that the variant CYP2C9*2 and CYP2C $9 * 3$ alleles, which are responsible for poor celecoxib metabolism, are relatively common in Caucasians $(\sim 35 \%)$ and far less prevalent in African-American and Asian populations $[25,26]$. The presence of poor metabolizers of celecoxib (i.e., with CYP2C $9 * 2$ and/or CYP2C $9 * 3$ mutant alleles) in these cohorts is unknown, which limits the explanation of observed higher plasma concentration or exposure in these studies. As the sample size in the current study was limited and the population comprised healthy young volunteers, the finding of a low $C_{\max }$ cannot definitely be attributed to population-related factors, and no other substantive conclusions can be drawn.

This is the first clinical study to characterize the pharmacokinetics of DFN-15 in healthy volunteers. It also provides useful benchmarks for future work with DFN-15 in patients with migraine. The main limitation of this study is that it used celecoxib $400 \mathrm{mg}$ under fasting conditions as the comparator, in observance of standard procedures in bioavailability studies [27], to show celecoxib release into the systemic circulation in the absence of variables such as food. Celecoxib 400-mg capsules are recommended to be taken with meals to improve bioavailability [12]. Had fed conditions been used for celecoxib capsules, the observed differences between celecoxib oral capsules and DFN-15 would have been more clinically meaningful. Another study is planned to evaluate the difference in bioavailability between DFN-15 given under fasting conditions versus celecoxib 400-mg capsules under fed conditions.

Because oral NSAIDs are a mainstay of acute migraine therapy, the present results appear to have clinical implications. The high rate of upper gastrointestinal complications seen with this class of medications, as well as the solubility-limited absorption of oral celecoxib, which can slow the onset of relief in patients with migraine, may inhibit wider usage in migraine. Cardiovascular safety can also be an issue, although the lower dosages and less frequent dosing (i.e., fewer than two per day) used in acute treatment of migraine appear to reduce the risk of cardiovascular complications by avoiding continuous interference with prostaglandin metabolism [28]. While currently available COX-2 inhibitors reduce the risk of gastrointestinal toxicity, they tend to be poorly and slowly absorbed in patients with migraine because of gastric stasis $[29,30]$. By providing a rapidly absorbed drug with an anticipated reduced risk of gastrointestinal and cardiovascular complications relative to nonselective NSAIDs, DFN-15 oral solution is expected to have a potentially important role as an acute migraine pharmacotherapy for patients whose attacks occur at work, in school, or upon awakening and require fast relief, as well as in those who respond to NSAIDs and prefer the convenience of oral dosing but have trouble swallowing tablets or capsules. To establish its potential benefits as an acute treatment, DFN15 is currently being evaluated in two pivotal studies in patients with episodic migraine. 


\section{Conclusions}

In this study, the peak plasma concentrations of celecoxib with all doses of DFN-15 oral solution were found to be higher than with the oral capsule formulation. DFN-15 was much more rapidly absorbed and eliminated than celecoxib $400-\mathrm{mg}$ oral capsules. DFN-15 was dose proportional across doses ranging from 120 to $240 \mathrm{mg}$. Overall, DFN-15 and celecoxib 400-mg capsules were safe and well tolerated. The potential clinical benefit of DFN-15, given its pharmacokinetic advantage, requires further validation in efficacy trials of episodic migraine.

Acknowledgements The authors wish to thank James Carlson, PharmD, for the overall clinical conduct of the study and Christopher Caiazza for medical writing services.

\section{Compliance with Ethical Standards}

Funding This study was sponsored by Dr. Reddy's Laboratories Ltd., which developed DFN-15.

Conflict of interest AP, SS, AG, and SM are employees of Dr. Reddy's Laboratories, developer of DFN-15; JN, MG, and JG were paid consultants of Dr. Reddy's Laboratories.

Ethical approval This study was conducted in compliance with the ethical principles of the Declaration of Helsinki (7th revision, 2013), the International Council for Harmonisation Guideline E6 for Good Clinical Practice, and the US FDA Code of Federal Regulations Title 21 (part 56). The protocol and the informed consent form were reviewed and approved by Quorum Review IRB (Seattle, WA, USA).

Informed consent All subjects voluntarily participated in this study. They signed an informed consent form, which explained the nature and objectives of the study as well as any known side effects and/or adverse reactions associated with study medications, after having fully comprehended its contents.

Open Access This article is distributed under the terms of the Creative Commons Attribution-NonCommercial 4.0 International License (http://creativecommons.org/licenses/by-nc/4.0/), which permits any noncommercial use, distribution, and reproduction in any medium, provided you give appropriate credit to the original author(s) and the source, provide a link to the Creative Commons license, and indicate if changes were made.

\section{References}

1. Silberstein SD. Practice parameter: Evidence-based guidelines for migraine headache (an evidence-based review): Report of the Quality Standards Subcommittee of the American Academy of Neurology. Neurology. 2000;55:754-62.

2. Marmura MJ, Silberstein SD, Schwedt TJ. The acute treatment of migraine in adults: the American Headache Society evidence assessment of migraine pharmacotherapies. Headache. 2015;55:3-20.

3. Lipton RB, Diamond S, Reed M, et al. Migraine diagnosis and treatment: results from the American Migraine Study II. Headache. 2001;41:638-45.
4. Lipton RB, Scher AI, Steiner TJ, et al. Patterns of health care utilization for migraine in England and in the United States. Neurology. 2003;60:441-8.

5. Lanas A, Garcia-Rodriguez LA, Arroyo MT, et al. Risk of upper gastrointestinal ulcer bleeding associated with selective cyclooxygenase- 2 inhibitors, traditional non-aspirin non-steroidal antiinflammatory drugs, aspirin and combinations. Gut. 2006;55:1731-8.

6. Misra UK, Jose M, Kalita J. Rofecoxib versus ibuprofen for acute treatment of migraine: A randomised placebo controlled trial. Postgrad Med J. 2004;80:720-3.

7. Laine L, Harper S, Simon T, et al. A randomized trial comparing the effect of rofecoxib, a cyclooxygenase 2-specific inhibitor, with that of ibuprofen on the gastroduodenal mucosa of patients with osteoarthritis. Gastroenterology. 1999;117:776-83.

8. Hawkey CJ, Laine L, Simon T, et al. Incidence of gastroduodenal ulcers in patients with rheumatoid arthritis after 12 weeks of rofecoxib, naproxen, or placebo: A multicentre, randomised, double blind study. Gut. 2003;52:820-6.

9. Loo CY, Tan HJ, Teh HS, et al. Randomised, open label, controlled trial of celecoxib in the treatment of acute migraine. Singap Med J. 2007;48:834-9.

10. Silberstein S, Tepper S, Brandes J, et al. Randomized, placebocontrolled trial of rofecoxib in the acute treatment of migraine. Neurology. 2004;62:1552-7.

11. Kudrow D, Thomas HM, Ruoff G, et al. Valdecoxib for treatment of a single, acute, moderate to severe migraine headache. Headache. 2005;45:1151-62.

12. Pfizer Inc. Celebrex (celecoxib capsule) [prescribing information]. http://labeling.pfizer.com/ShowLabeling.aspx?id=793. Accessed 26 May 2017

13. Lipton RB, Hamelsky SW, Dayno JM. What do patients with migraine want from acute migraine treatment? Headache. 2002;42(Suppl 1):3-9.

14. Aurora SK, Papapetropoulos S, Kori SH, et al. Gastric stasis in migraineurs: etiology, characteristics, and clinical and therapeutic implications. Cephalalgia. 2013;33:408-15.

15. Volans GN. Migraine and drug absorption. Clin Pharmacokinet. 1978;3:313-8.

16. Tokola RA, Neuvonen PJ. Effect of migraine attacks on paracetamol absorption. Br J Clin Pharmacol. 1984;18:867-71.

17. Aurora $S$, Kori $S$, Barrodale $P$, et al. Gastric stasis occurs in spontaneous, visually induced, and interictal migraine. Headache. 2007:47:1443-6.

18. US Food and Drug Administration. Inactive ingredients database. https://www.fda.gov/drugs/informationondrugs/ucm113978.htm. Accessed 26 May 2017

19. US Food and Drug Administration. Guidance for industry: bioanalytical method validation. https://www.fda.gov/downloads/ Drugs/Guidance/ucm070107.pdf. Accessed 26 May 2017

20. Schuirmann DJ. A comparison of the two one-sided tests procedure and the power approach for assessing the equivalence of average bioavailability. J Pharmacokinet Biopharm. 1987; 15:657-80.

21. Center for Drug Evaluation and Research. Clinical pharmacology/biopharmaceutics review: Imitrex ${ }^{\circledR}$ (sumatriptan) tablets, NDA 20-132. http://www.accessdata.fda.gov/drugsatfda_docs/ nda/2003/020132_S015_IMITREX\%20TABLETS_BIOPHARMR. pdf. Accessed 26 May 2017

22. US Food and Drug Administration. Clinical pharmacology review: rizatriptan benzoate (MAXALT-MLT ${ }^{\circledR}$, sNDA 20-865/020. http://www.fda.gov/downloads/Drugs/DevelopmentApproval Process/DevelopmentResources/UCM289415.pdf. Accessed 26 May 2017 
23. Itthipanichpong $\mathrm{C}$, Chompootaweep $\mathrm{S}$, Wittayalertpanya $\mathrm{S}$, et al. Clinical pharmacokinetic of celecoxib in healthy Thai volunteers. J Med Assoc Thai. 2005;88:632-8.

24. Jayasagar G, Krishna Kumar M, Chandrasekhar K, et al. Influence of rifampicin pretreatment on the pharmacokinetics of celecoxib in healthy male volunteers. Drug Metabol Drug Interact. 2003;19:287-95.

25. Lee CR, Goldstein JA, Pieper JA. Cytochrome p450 2c9 polymorphisms: a comprehensive review of the in-vitro and human data. Pharmacogenetics. 2002;12:251-63.

26. Scordo MG, Aklillu E, Yasar U, et al. Genetic polymorphism of cytochrome p450 2c9 in a caucasian and a black african population. Br J Clin Pharmacol. 2001;52:447-50.

27. US Food and Drug Administration. Guidance for industry. Bioavailability and bioequivalence studies for orally administered drug products - general considerations. https://www.fda.gov/ ohrms/dockets/ac/03/briefing/3995B1_07_GFI-BioAvail-BioEquiv. pdf. Accessed 26 May 2017

28. Solomon SD, Wittes J, Finn PV, et al. Cardiovascular risk of celecoxib in 6 randomized placebo-controlled trials: the cross trial safety analysis. Circulation. 2008;117:2104-13.

29. Shechter A, Stewart WF, Silberstein SD, et al. Migraine and autonomic nervous system function: a population-based, casecontrol study. Neurology. 2002;58:422-7.

30. Aurora SK, Kori SH, Barrodale P, et al. Gastric stasis in migraine: more than just a paroxysmal abnormality during a migraine attack. Headache. 2006;46:57-63. 